\title{
Made to Stick: Why Some Ideas Survive and Others Die
}

\author{
By Chip Heath \& Dan Heath \\ Random House, New York 2007, 291 pages
}

Reviewed by

Jessica A. Hale (jhale15@wccnet.edu), Student Adviser, Orientation, Washtenaw Community College

Ever heard of the kidney heist? Or the Halloween candy booby-trapped with razor blades? Want to make orientation as memorable as these urban legends? This book provides simple and effective ways to do just that. For orientation professionals, the challenge of presenting a volume of important information in a very small amount of time and making it stick is often daunting. Too frequently, stories of students who walk into other departments and say things like "No one ever told me that!" are circulated around campus, giving pause to individuals that know that the material in question was covered in orientation. The book is a call to action and a beacon of hope for anyone interested in making their messages more salient and memorable.

Made to Stick is based on the idea that some ideas are more memorable or "sticky," than others. "Stickiness" is a concept borrowed from Malcolm Gladwell's book on social phenomena, The Tipping Point. According to the authors, "stickiness" occurs when ideas are "understood and remembered, and they have a lasting impact - they change your audience's opinions or behavior." Both Dan and Chip Heath have spent the last decade exploring this topic from multiple angles. Chip Heath, a professor of organizational behavior at Stanford University, spent years doing extensive research on urban legends and topics like, why Nostradamus' prophecies are still read, why Chicken Soup for the Soul stories are inspirational, and why ineffective folk remedies persist. Dan Heath, a former Harvard researcher, studied the most effective teaching techniques of the nation's top instructors as a part of his research for Thinkwell, the multimedia textbook company he founded. Through their collective experience, the Heath brothers have come up with six factors that seem to affect the stickiness of an idea: simplicity, unexpectedness, concreteness, credibility, emotions, and stories. These factors can easily be recalled using the acronym SUCCESs (a pneumonic device designed by the authors to make their message stick). Each chapter contains a myriad of examples, exercises, and illustrations to help the reader understand and remember the messages presented. The result is a "sticky" message that the reader will be eager to share.

Chapter One of the Heath brothers' creation addresses the need for messages to be simple and get at the core of the idea being communicated. This is easier said 
than done. There are often multiple agendas or multiple messages being relayed at once, but the power of a simple message comes from its singularity. In the words of the authors, simplicity is about "discarding a lot of great insights in order to let the most important thing shine." This is critical because it's "hard to make ideas stick in noisy, unpredictable, chaotic environments" (read: orientation). Think of a core message like the Commander's Intent, "If we do nothing else in today's mission, we must ." By reducing the number of signals being sent, there is an increased likelihood that the desired signal will be received.

Chapter Two speaks to the need for a sticky idea to be unexpected. What does it take to spark people's interest? The Heath brothers suggest that curiosity can be stimulated by presenting gaps in knowledge, i.e., "pointing out something someone else knows that they don't." By posing questions or puzzles rather than presenting facts, audiences can be inspired to engage with the material just as they would a good mystery novel (i.e., "What will happen? Was I right?").

The third chapter of the book identifies concreteness as another critical component of a sticky idea. Ideas that are abstract are harder to understand and interpret. To make messages sticky, one must find ways to make the ideas easy to visualize and closely connected to real life experience. One of the examples presented in support of this idea is the well known discrimination simulation, "blue-eyed, brown-eyed," created by Jane Elliot, an elementary school teacher in the wake of the assassination of Martin Luther King, Jr. Students in this class were able to experience the effects of discrimination in a tangible and poignant way, the end result being that even 15 years after the simulation, participants felt it was one of the most profound learning experiences they had ever had. Making audiences experience a message increases the likelihood the message will be retained. In the words of the authors, "Language is abstract, but life is not abstract." Additionally, concrete ideas make it easier to coordinate action, so by making ideas concrete it contributes to more efficient teams (like our orientation teams).

Chapter Four of Made to Stick addresses the issue of credibility. What makes people believe an idea? Making people believe an idea can be one of the greatest challenges in making an idea sticky. There are two kinds of credibility to contend with, internal and external. External credibility can be facilitated by authority figures such as experts, celebrities, and even anti-authority figures who have learned the credibility of the message the hard way. Internal validity, on the other hand, can come from a variety of sources including convincing details, accessible statistics, testable credentials ("try before you buy"), and individual examples or testimonies that illustrate the point. By tapping into both internal and external sources of credibility, the likelihood that messages will be received well increases.

Chapter Five addresses the emotional component of a sticky idea: How do you make people care? According to the authors, "Feelings inspire people to act." There are a number of ways to make people care, including piggybacking on the emotions of other ideas, appealing to self-interest ("What's in it for me?"), and appealing to identity ("Don't mess with Texas"). To identify the desired emotion content of a message, the Heath brothers suggest asking "Why?" In doing so, we may be better able to connect to the message to the "core values, the core 
principles, that underlie our ideas."

The final chapter of Made to Stick discusses the value of stories in making an idea sticky. Stories can be teaching tools, providing a "simulation," or knowledge about how to act. Research on the brain has shown that the same parts of the brain are activated in imagining the activity/event that are stimulated in experiencing the activity/event. This means that stories can prepare people for action (i.e., listening to stories of successful students can help other students prepare for success). In addition, stories can create inspiration, a burst of energy, and call to action for people to change (think Jared and Subway). Using stories provides an intuitive way to follow the SUCCESs principles and allows presenters to draw relevant examples from real world experience.

The authors of this book have certainly employed their suggestions in the writing of this book. The chapters and principles are easy to remember and intuitive. The tone of the book lends itself to a wide audience and would make an excellent professional development tool for orientation staff as well as faculty. The principles addressed in Made to Stick have natural application in the development of orientation themes, presentations, and printed materials. As more research is done to illuminate generational learning styles, creating messages that cut across ages and learning styles will grow in importance. This book will provide excellent "food for thought" for any higher education professionals interested in making their messages as sticky as duct tape. 